\title{
Usage of Numerical Optimization in Wind Turbine Airfoil Design
}

\author{
F. Grasso \\ Presented at the $28^{\text {th }}$ AIAA Applied Aerodynamics Conference, AIAA, \\ 28 June - 1 July, 2010, Chicago, II., USA
}



28th AIAA Applied Aerodynamics Conference

Aerodynamic design: analysis, methodologies,\& optimization techniques

\title{
Usage of Numerical Optimization in Wind Turbine Airfoil Design
}

\author{
F. Grasso ${ }^{1}$ \\ Energy Research Centre of the Netherlands (ECN), 1755 LE, Petten, The Netherlands
}

\begin{abstract}
One important key element in the aerodynamic design of wind turbines is the use of specially tailored airfoils to increase the ratio of energy capture to the loading and thereby to reduce cost of energy. This work is focused on the design of wind turbine airfoil by using numerical optimization. Firstly, the requirements for this class of airfoils are illustrated and discussed in order to have an exhaustive outline of the complexity of the problem. Then, the optimization approach is presented; a gradient based algorithm is used, coupled with RFOIL solver and a composite Bezier geometrical parameterization. A particularly sensitive point is the choice and implementation of constraints; in order to formalize in the most complete and effective way the design requirements, the effects of activating specific constraints are discussed. Finally, a numerical example regarding the design of a high efficiency airfoil for the outer part of a blade is illustrated and the results are compared with existing wind turbine airfoils.
\end{abstract}

\section{Nomenclature}

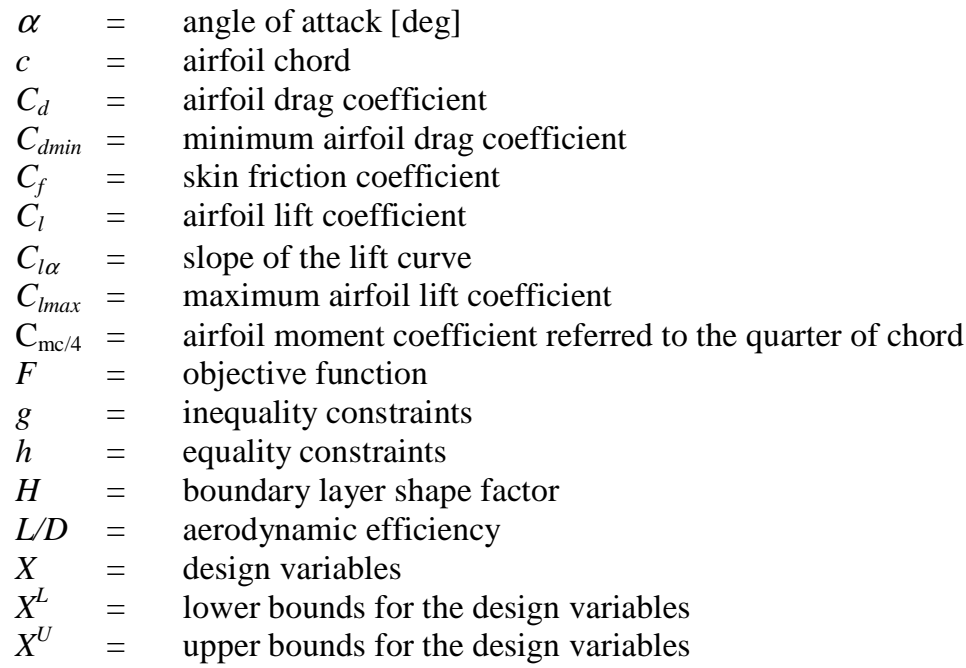

\section{Introduction}

D ESIGN of airfoils specifically suited for wind turbine blade applications is important in the continuing development of wind turbines. In the modern wind turbines, some aviation airfoils like NACA-63XXX and NACA-

\footnotetext{
${ }^{1}$ Postdoctoral Aerodynamicist, Wind Energy Unit, Rotor and Farm Aerodynamics Group, Westerduinweg 3; grasso@ecn.nl, Associate Fellow AIAA
} 
64XXX are still quite frequently used, but, more and more, new airfoils families for wind turbines are developed because of the intrinsic requirements in terms of design point, off-design capabilities and structural properties.

The development of wind turbine airfoils was intensified in the middle 1980's when Tangler and Somers developed numerous airfoils. An overview of available NREL airfoils can be found in [1]. Björk [2] and Timmer and van Rooij [3] have made other significant contributions to this field. The development of the Ris $\emptyset$ airfoils was initiated in the middle 1990's and has until now led to the design of three airfoil families [4].

The target design characteristics for the airfoils have been updated during the years and tailored to the specific type of power control and the need for off-design operation. The desirable airfoil characteristics can be divided into structural and aerodynamic properties and the wind turbine blade can be divided into the root, mid and tip parts where the root part is mainly determined from structural considerations. In contrast, the tip part is determined from aerodynamic considerations.

This work is focused on the design of a wind turbine dedicated airfoil for the tip region of the blade, by using numerical optimization. In the next section, the requirements for this class of airfoils are presented, then the used approach is explained. Finally, the design of the new airfoil is described and the results are discussed.

\section{Airfoils for Wind Turbines}

Airfoil characteristics include both aerodynamic and structural requirements. For the outer part of the blade, the most important parameters, from the structural point of view, are the maximum airfoil thickness and the chord-wise location of the maximum thickness. The thickness of the profile must be able to accommodate the structure necessary for blade strength and stiffness. Depending of the class of the wind turbine, certain values for the thickness along the blade can be expected and this fact introduces a first indication for the design problem. In case of Mega-Watt class wind turbine, for example, a realistic value for the relative thickness at the tip can be around $18 \%$ of the chord. The location of the maximum thickness along the chord is also important; when an airfoil is designed, also the other ones along the blade should be considered to guarantee constructive compatibility. This means that, in order to allow the spar passing through the blade, the chord-wise position of the thickness should be similar for the complete blade.

From the aerodynamic point of view the most important parameter for the tip region is the aerodynamic efficiency $(L D)$. In order to obtain good turbine performance, the aerodynamic efficiency should be as high as 
possible, but, at the same time, other considerations should be taken into account. One consideration is related with the stall behavior and the $C_{l \max }$. Some of the existing airfoils for wind turbines have also a high value of $C_{\text {lmax }}$ and a relative high value for the design $C_{l}$; this means that, for a certain load, a smaller chord is necessary. This reduces loads under parked conditions at high wind speeds. A lower chord in the outboard sections also reduces weight. In addition to this, a high $C_{l}$ value (and lower associated chord $c$ ) in the outboard sections reduces the amplitude of load fluctuations resulting from wind gusts. Hence a high $C_{l}$ is desirable to reduce fatigue and parking loads and can save weight. On the other hand, the stall can be abrupt and undesirable vibrations can be induced on the blade. So, it is important that the transition and the separation move gradually when the angle of attack increases. Another important consideration is related with the sensitivity of the airfoil to the roughness. An airfoil with a large laminar flow extension will be very efficient in "clean" conditions, but very bad in case of "dirty" conditions. Also the $C_{m c / 4}$ should be taken into account because large values of moment coefficient will give higher torsion moment on the blade; for pitch regulated wind turbines, small values for $C_{m c / 4}$ mean a reduction in control forces. Also in this case, the other airfoils used on the blade should be considered in order to have a similar value for the moment coefficient; this will prevent the rotor from "irregular" performances along the blade coming from too different airfoils. This is one of the reasons why, more than in aviation, the trend in airfoil design is to develop families of airfoils. The last problem that should be taken into account in developing airfoils for wind turbines is connected with gusts. Because of gusts, the local angle of attack for the single airfoil can suddenly change and be in pre-stall or stall zone. So, it is important to keep good off-design performances and try to have a angle of attack range between the design angle of attack and the one for which, noticeable separation occurs on the airfoil.

\section{Numerical Optimization Approach}

In order to design airfoils, several methodologies can be used. A very popular approach is the inverse design technique, proposed by Lighthill and widely developed by Eppler [5, 6] and Drela [7, 8]. The basic principle of this design method is that, the pressure coefficient on the airfoil surface is prescribed and the airfoil geometry is created; by iteratively modifying the pressure distribution on the airfoil surface, the designer can generate the geometry of an airfoil that satisfies the requirements. Despite its large use, there are several disadvantages associated with this technique; the most evident is that it is very difficult to take into account at the same time multiple requirements, especially when they concern different disciplines. 
A valid alternative to solve this problem is the usage of multidisciplinary design optimization (MDO) approach. In the most general sense, numerical optimization $[9,10]$ solves the nonlinear, constrained problem to find the set of design variables, $X_{i}, \mathrm{i}=1, \mathrm{~N}$, contained in vector $\boldsymbol{X}$, that will:

Minimize $F(X)$

subject to:

$$
\begin{aligned}
& g_{j}(X) \leq 0 \quad j=1, M(2) \\
& h_{k}(X)=0 \quad k=1, L \\
& X_{i}^{L} \leq X_{i} \leq X_{i}^{U} \quad i=1, N
\end{aligned}
$$

Equation 1 defines the objective function which depends on the values of the design variables, $\boldsymbol{X}$. Equations 2 and 3 are inequality and equality constraints respectively (equality constraints can be written as inequality constraints and included in equation 2), and equation 4 defines the region of search for the minimum. The bounds defined for each degree of freedom by equation 4 are referred to side constraints.

\section{A. Geometry Description}

One of the most important ingredients in numerical optimization is the choice of design variables and the parameterization of our system in using these variables. In order to reduce the number of necessary parameters to take into account to describe the airfoil's shape, but without loss of information about the geometrical characteristics of the airfoil, several mathematical formulations were proposed in literature [11]. In the present work, a composite third order Bezier is used. Basically, the airfoil is divided in four parts and for each part, a third order Bezier curve is used to describe the geometry. The advantage of this choice is the possibility to conjugate the properties of Bezier functions in terms of regularity of the curve and easy usage, with a piecewise structure that allows also local modifications to the geometry. The complete description can be found in [12]; a representative sketch is illustrated in Fig. 1; the points between 1 and 4 define the first Bezier curve, the ones between 4 and 7 the second curve and so on. In total, 13 control points are used to describe the airfoil geometry, that means 26 degrees of freedom. In practice, however, the leading edge is fixed (control point 7), as well as the abscissa of the trailing edge (control points 1 and 13); the abscissas of control points 6 and 8 are also fixed in order to maintain the curvature continuity at the leading edge and the control points 4 and 10 are directly controlled by the algorithm to keep the curvature continuity between two different Bezier curves. Fourteen degrees of freedom are actively used in the design process. 


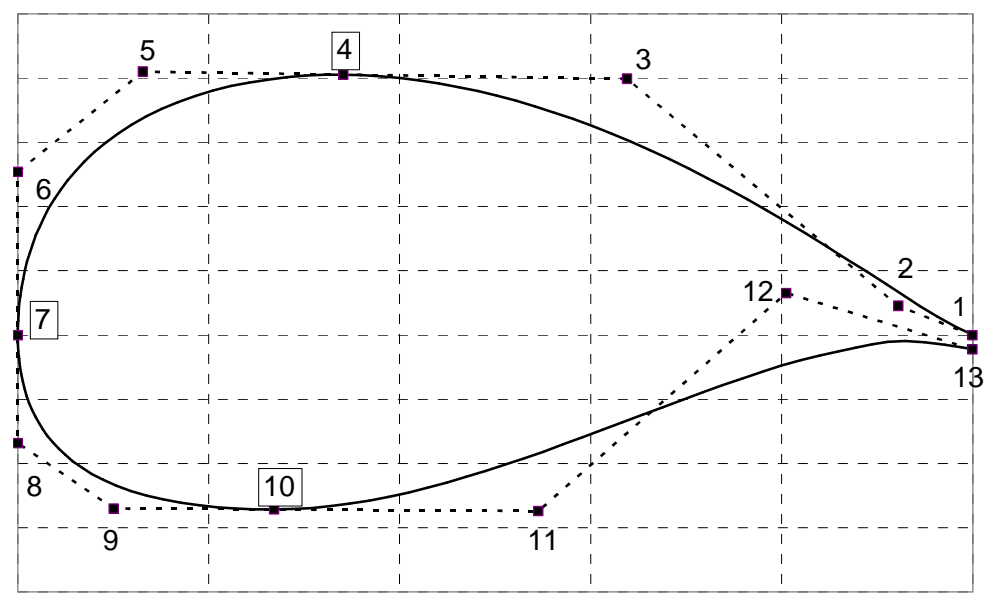

Fig. 1 Geometry parameterization example.

\section{B. Optimization Algorithm}

The choice of optimization algorithm is very important because the final results are usually dependent on the specific algorithm in terms of accuracy and local minima sensitivity. Evolutionary algorithms are less sensitive to local minima; however, they are time consuming and constraints have to be included as a penalty term to the objective function. On the other hand, gradient based algorithms can lack in global optimality but allow multiple constraints and are more robust, especially for problems in which a large number of constraints are prescribed. In this investigation, the advanced NLPQP gradient based algorithm from Schittkowsky [13] is implemented and the gradients are approximated by finite differences.

\section{Objective Function Evaluation}

Since the optimization process requires many evaluations of the objective function and the constraints before an optimum design is obtained, the computational costs cannot be neglected, as well as the accuracy of the results. Here, the RFOIL [14] numerical code is used. RFOIL is a modified version of XFOIL [15] featuring an improved prediction around the maximum lift coefficient and capabilities of predicting the effect of rotation on airfoil characteristics. Regarding the maximum lift in particular, numerical stability improvements were obtained by using the Schlichting velocity profiles for the turbulent boundary layer, instead of Swafford's. Furthermore, the shear lag coefficient in Green's lag entrainment equation of the turbulent boundary layer model was adjusted and deviation from the equilibrium flow has been coupled to the shape factor of the boundary layer. The following figures 
illustrate a comparison with experimental data [16] for the NACA- $633_{3} 418$ airfoil. The Reynolds number is 6 million and the transition is free.

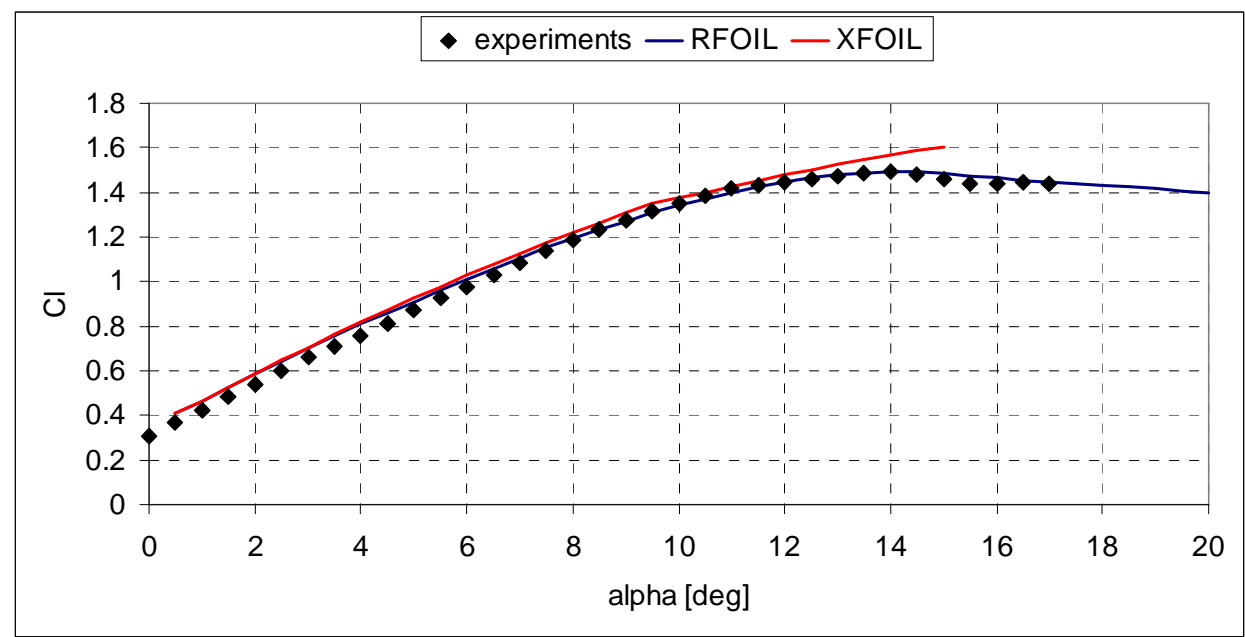

Fig. 2 Lift curve for the NACA-63 418 airfoil; comparison between XFOIL and RFOIL with experiments [16]. Reynolds number 6 million, free transition.

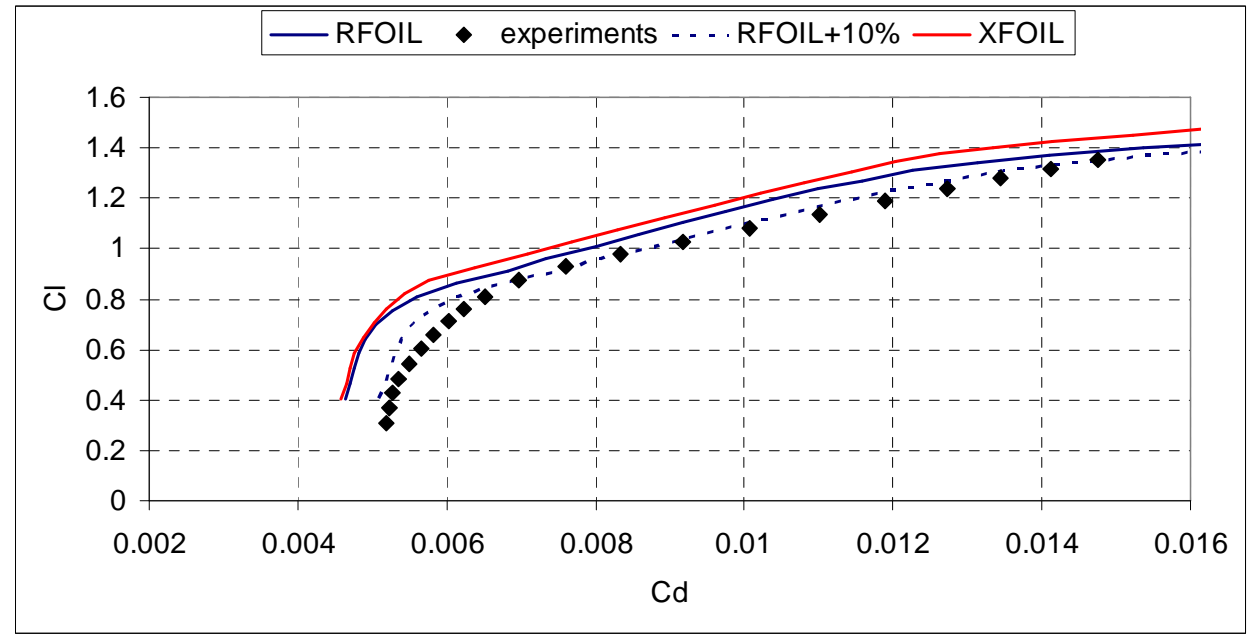

Fig. 3 Drag curve for the NACA-63 418 airfoil; comparison between XFOIL and RFOIL with experiments [16]. Reynolds number 6 million, free transition.

It should be noted that the RFOIL prediction for the stall region is well described and very close to the experimental data; in XFOIL results, only the deviation from the linear zone is described but not the stall. For the drag curve, XFOIL and RFOIL are very close to each other for small values of $C_{l}$, but for high $C_{l}$, XFOIL is under predicting. In ref [14], a additional drag of $10 \%$ is suggested to correct the RFOIL data; by adding this factor, a very 
good agreement is found also for the drag coefficient. In order to have more realistic predictions, this $10 \%$ drag penalty is added during the optimization process and for all the numerical analyses.

\section{Design of tip region airfoil}

The design of a new airfoil is presented in this section. As anticipated in the previous paragraphs, the requirements for the tip region of the blade are considered. A Mega-Watt class wind turbine is chosen as reference; the Reynolds number is 6 million and the airfoil is designed to maximize the aerodynamic efficiency at 7 degrees of angle of attack.

The NACA0012 airfoil was used as baseline for the optimization. The purpose of this choice is to have a starting point for the design process, as far as possible from potential local solutions and, in this way, have more confidence on the optimality of the solution.

\section{A. Geometrical Constraints}

Usually, the thickness at the tip is between $15 \%$ and $18 \%$ of the chord; here a minimum value of $18 \%$ is prescribed and a chord-wise location around $30 \%$ of the chord in order to be compatible with existing airfoils. As consequence, it should be noted that, because of the $12 \%$ thickness, the baseline is even out of the feasible domain.

A minimum trailing edge thickness of $0.25 \%$ of the chord is required to ensure airfoil's feasibility from manufacturing point of view.

One of the problems outlined in the previous sections is the insensitivity for the roughness and the need to have a smooth stall, with gradual transition and separation. By using the results of ESDU [17], extension from Gault [18], a minimum value for the ordinate at $\mathrm{x} / \mathrm{c}$ equal to $0.0125 \mathrm{c}$ can be selected to ensure a trailing edge separation. From this parameter, a minimum LE radius of $0.015 \mathrm{c}$ can be assigned. The main advantage of this choice is the fact that the stall is included in the design process by connecting it to a geometrical parameter; this means that the result is not affected by eventual numerical inaccuracy and it is not necessary to perform aerodynamic analyses at stall conditions. However, due to the importance of the stall behaviour and in order to do not force the solution by restricting too much the domain, it is preferred to take into account the stall characteristics introducing an aerodynamic constraint.

\section{B. Aerodynamic Constraints}

In order to limit the blade torsion, a minimum value for $C_{m c / 4}$ of -0.08 is prescribed. This value comes from a comparative analysis on experimental data $[3,16]$ for existing airfoils realistically usable for this class of turbines. 
The geometries considered are the DU-W2-401, the DU-W2-350, the DU97-w-300, the DU-W2-250 and the NACA-63 421 . It should be noted that, apart the DU-W2-250 airfoil, the chosen value for the moment coefficient is reasonable.

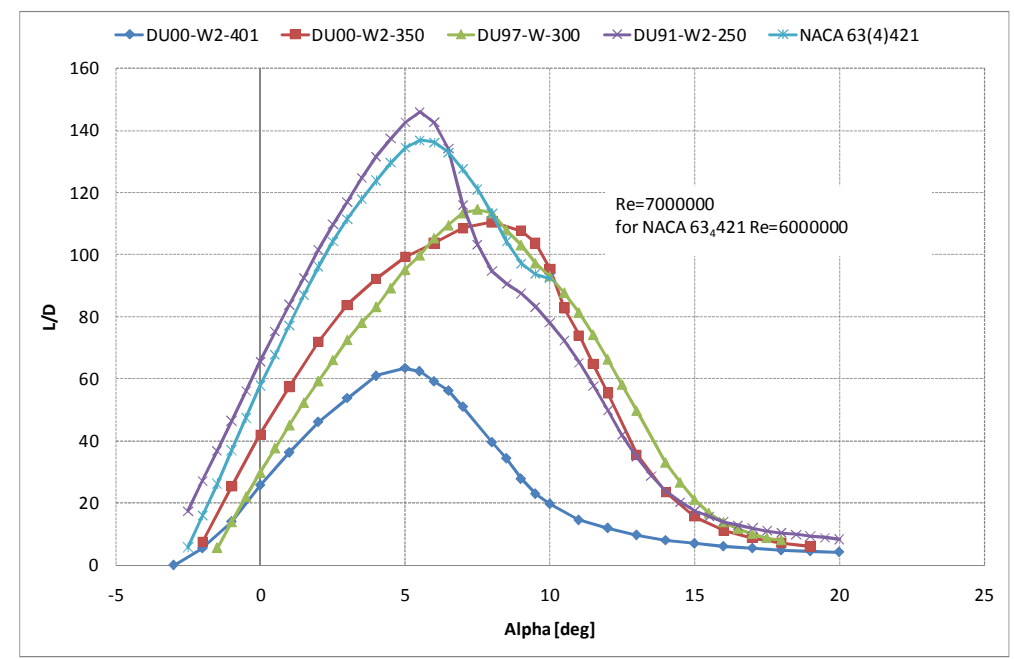

Fig. 4 Efficiency curve for selected airfoils. $\mathrm{Re}=7$ million, for $\mathrm{NACA63}_{4} 421 \mathrm{Re}=6$ million. Experimental data $[3,16]$.

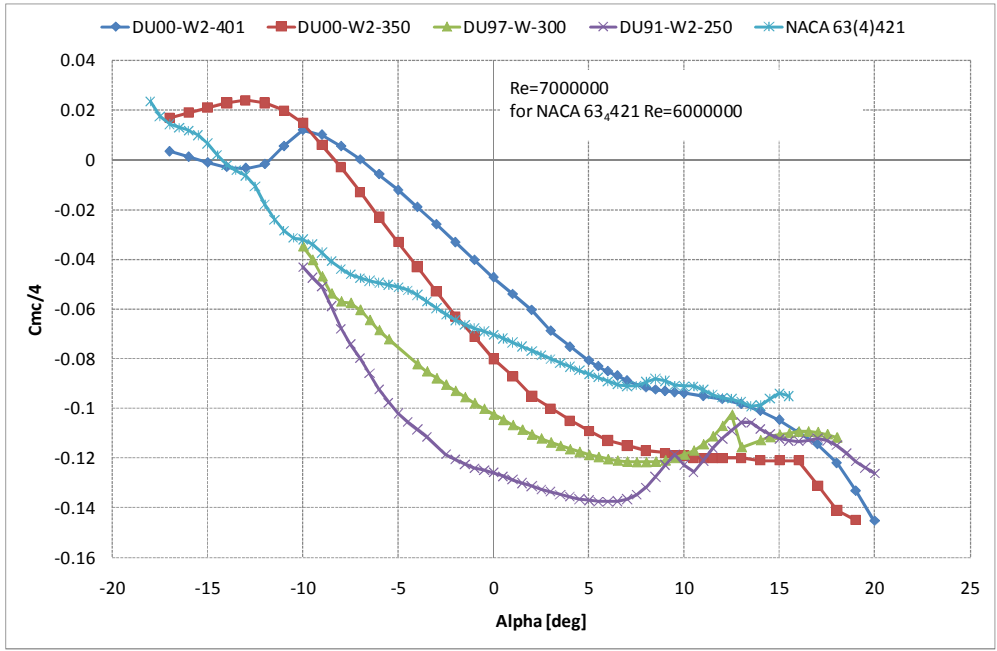

Fig. 5 Moment coefficient curve for selected airfoils. $\mathrm{Re}=7$ million, for $\mathrm{NACA63} 421 \mathrm{Re}=6$ million. Experimental data [3, 16].

Regarding the problems related with the gusts, a range of minimum 7 degrees is required between the design angle of attack and the start of significant separation. This is done by imposing that the position of the separation 
point on the suction side, based on the shape factor $(H)$ equal to 2.8 , is at minimum $90 \%$ of the chord at angle of attack equal to 14 degrees.

To avoid possibility of abrupt stall and converge to a solution in which a Stratford style recompression is not present (it can lead to a not gradual evolution in transition location), the design is performed by fixing transition at $0.01 \mathrm{c}$ on the suction side and $0.1 \mathrm{c}$ on the pressure side. The optimization process in fixed transition conditions, together with the above mentioned constraint related with the location of the separation, should give reasonably good results about stall characteristics. The drawback of this solution is the increase in time of the optimization process, due to the fact that for each iteration, the complete lift curve up to the stall condition needs to be calculated to ensure the accuracy of results and not just the design condition.

\section{Results}

Fig. 6 shows the comparison between the new airfoil, named GWA1-18, and NACA6 $3_{3} 418$, NACA64 3418 , NACA63 618 and NACA64 3618 airfoils.

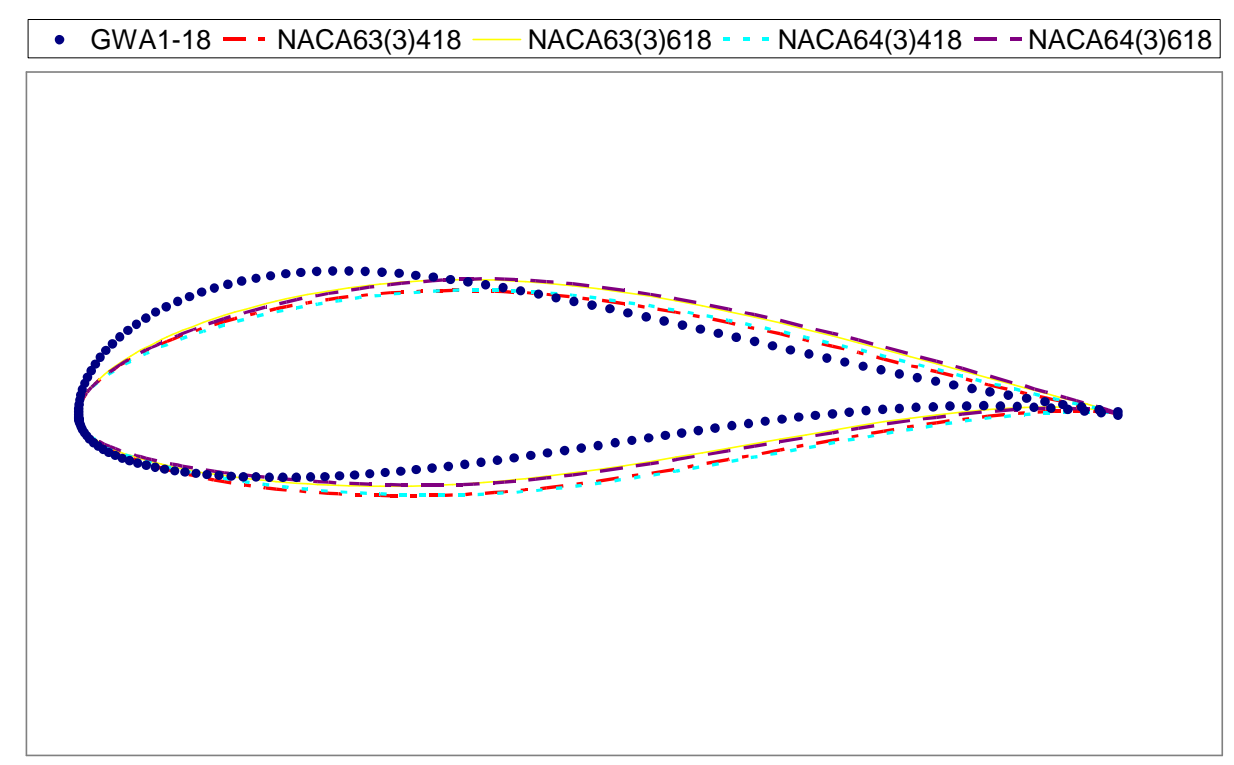

Fig. 6 GWA1-18 airfoil compared with NACA geometries.

In Fig. 7 and Fig. 8, the aerodynamic characteristics are compared. A value for the maximum efficiency greater than 150 is reached, achieving, at the same time, a good off-design performance, especially if compared to the peaky performances of NACA airfoils. In the figures also the experimental data are used to show the general reliability of RFOIL. In absence of wind tunnel tests, this fact should give some confidence about the robustness of the GWA1-18 
airfoil data. The moment coefficient is respecting the imposed bound, as well as, the separation that occurs not before the stall at 15 degrees (Fig. 9, Fig. 10). Looking at the lift coefficient curve, it can be seen that good high lift characteristics have been obtained with a not abrupt stall. The high lift characteristics allows to reduce the chord, so it is beneficial to design a slender and lighter blade, reducing also the loads along the blade. Due to the large extension of the linear region of the lift curve, the slope of the curve is constant up to the stall. This means that also the fatigue loads, due to variation of $C_{l}$, thus of $C_{l \alpha}$, will be reduced.

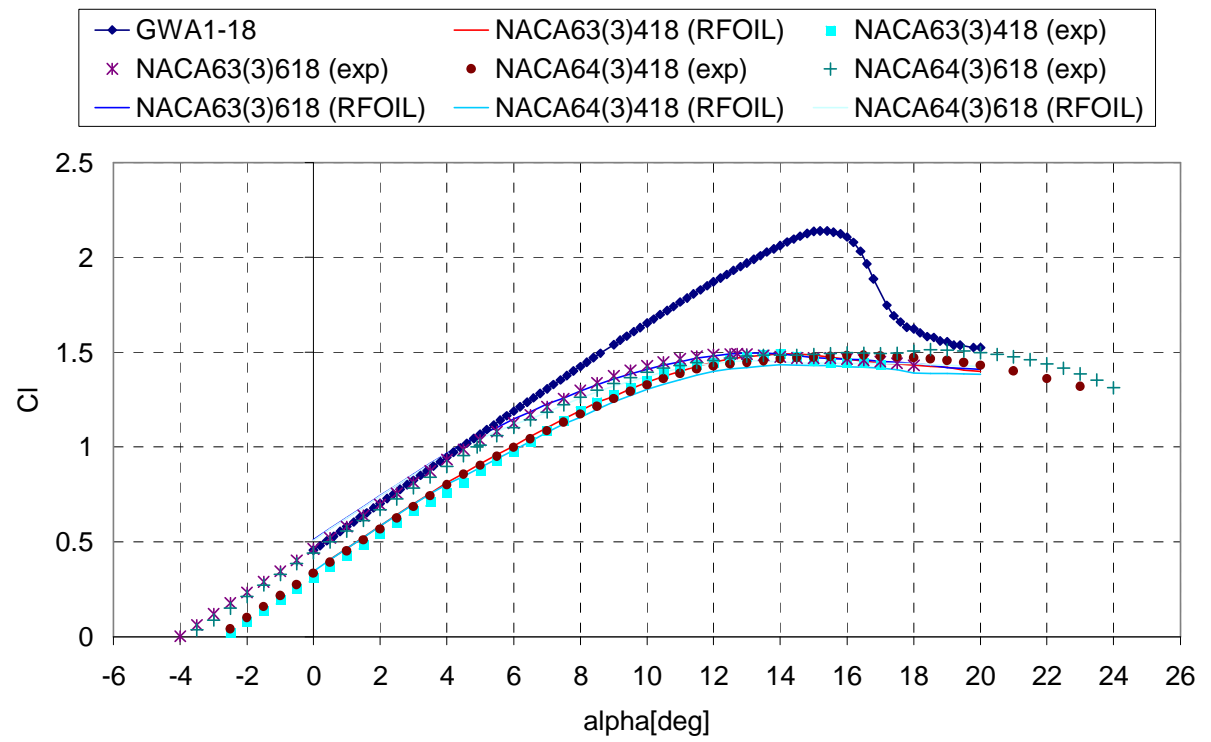

Fig. 7 Lift coefficient curve; comparison between the GWA1-18 and NACA airfoils. $\mathrm{Re}=6 \mathrm{million}$, free transition, RFOIL predictions. Experimental data from Abbott [16]. 


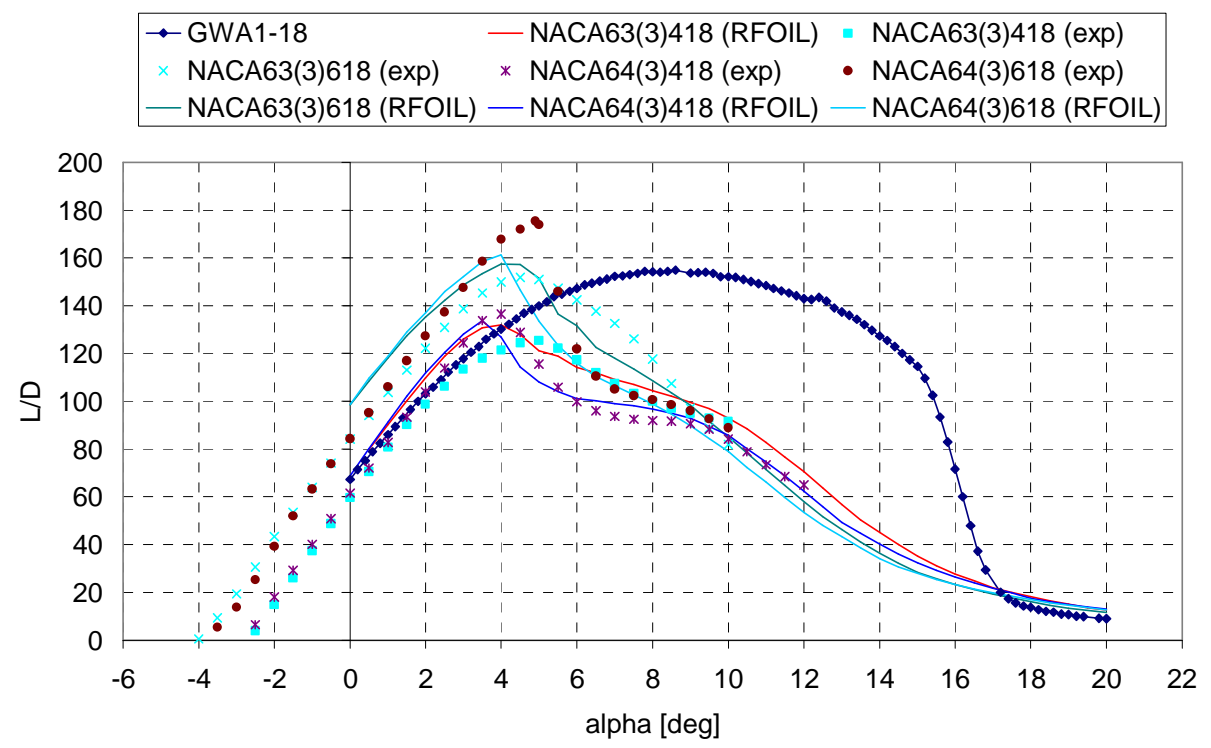

Fig. 8 Efficiency curve; comparison between the GWA1-18 and NACA airfoils. Re=6 million, free transition, RFOIL predictions. Experimental data from Abbott [16].

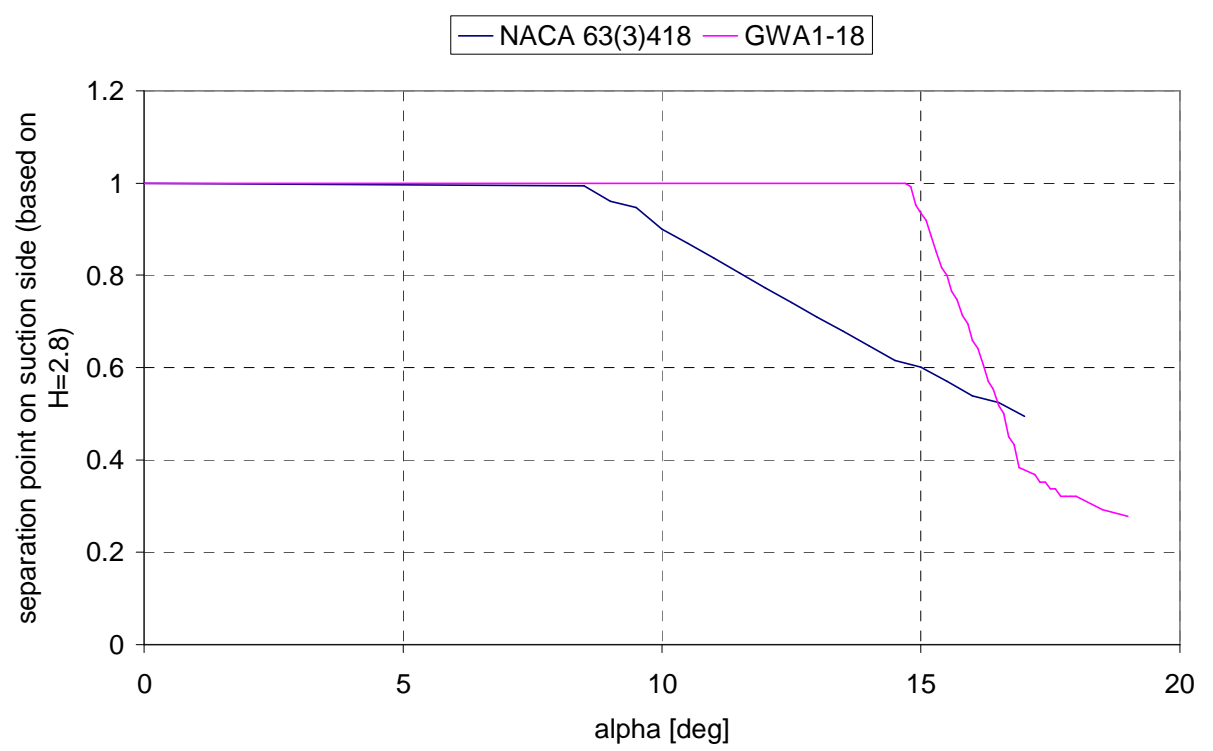

Fig. 9 Separation evolution by varying the angle of attack for the GWA1-18 airfoil. RFOIL predictions based on $\mathbf{H}=\mathbf{2 . 8}$. 


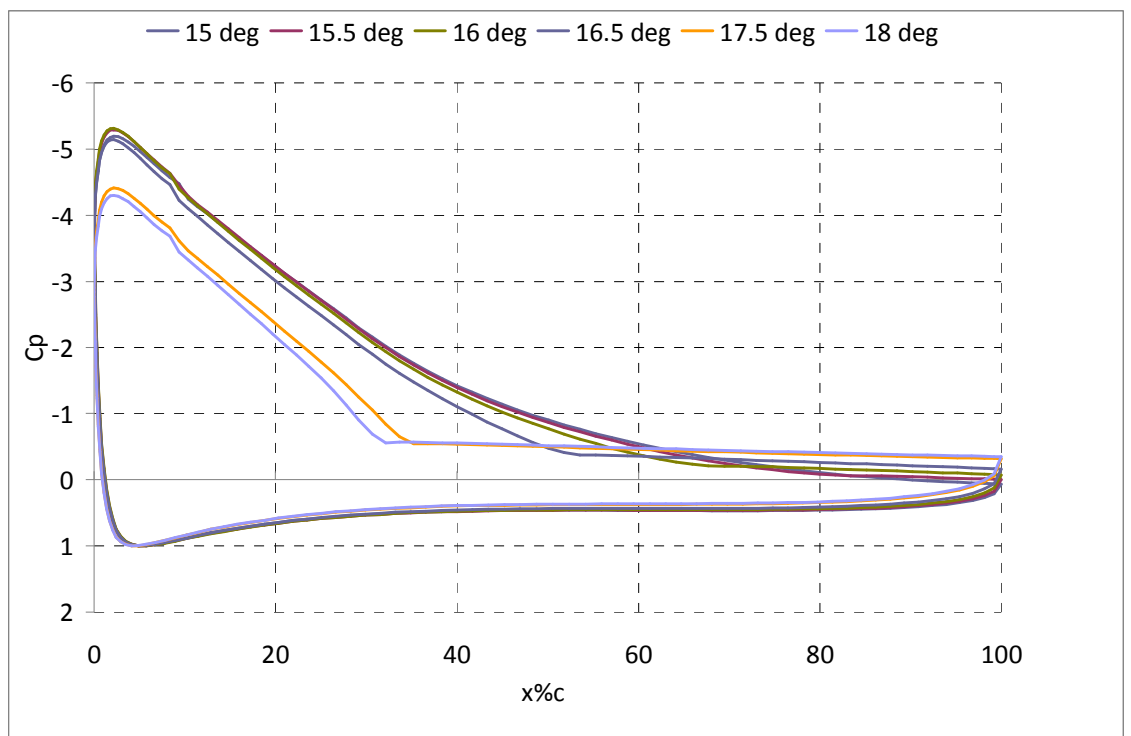

Fig. 10 Pressure coefficient distribution on GWA1-18 airfoil. RFOIL predictions, Reynolds number 6 million, free transition.

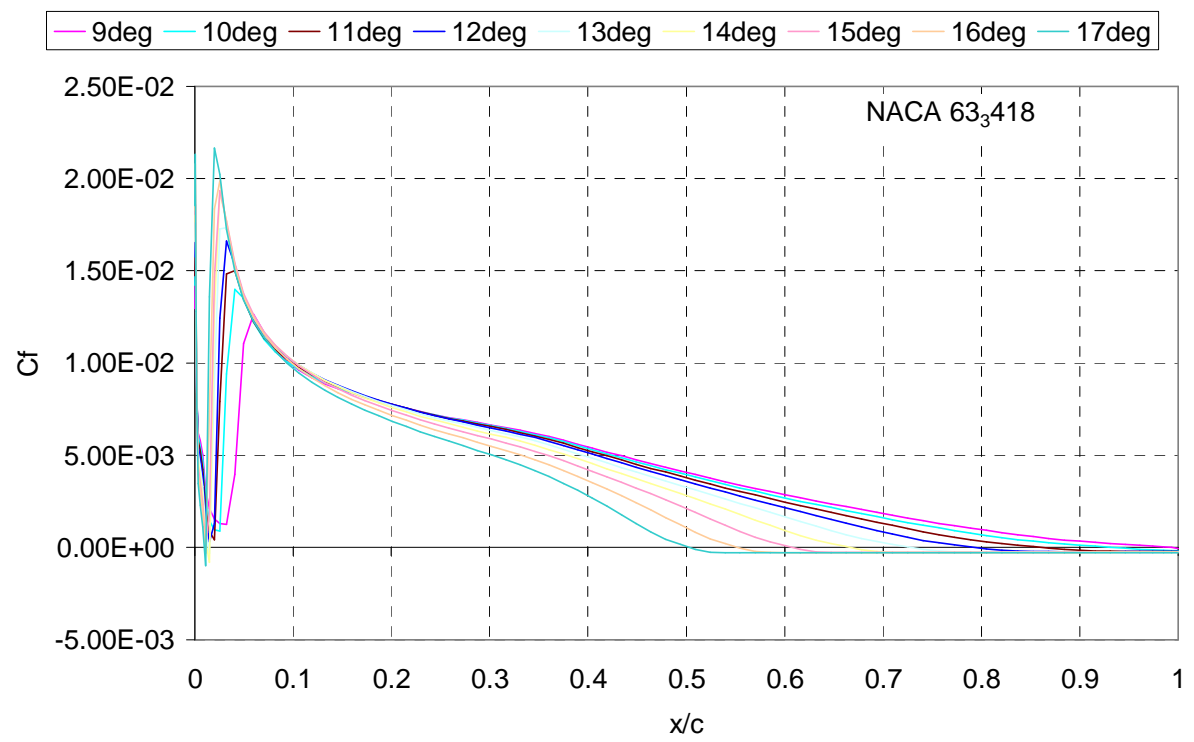

Fig. $11 C_{\mathrm{f}}$ change due to the angle of attack for the $\mathrm{NACA63}_{3} 418$ airfoil. RFOIL predictions, $\mathrm{Re}=6 \mathrm{million}$, free transition. 


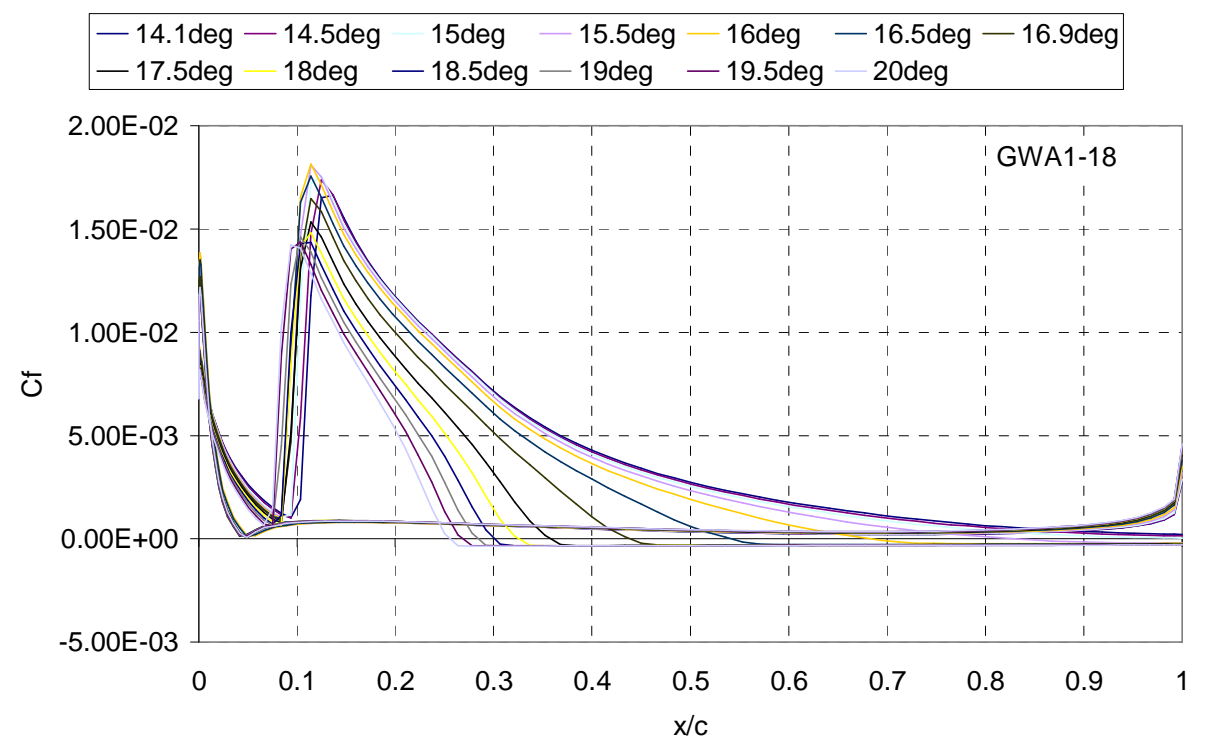

Fig. $12 \mathrm{C}_{\mathrm{f}}$ change due to the angle of attack for the GWA1-18 airfoil. RFOIL predictions, $\operatorname{Re}=6$ million, free transition.

\section{Effects of roughness}

The airfoils are compared also by simulating the presence of roughness; the analysis was performed by imposing the transition at $0.01 \mathrm{c}$ on the top surface and at $0.1 \mathrm{c}$ on the lower surface. It should be noted that the performance of the GWA1-18 in dirty conditions is better than the NACA airfoils performance and the loss in efficiency due to the imposed transition is less than for the NACA geometries. An interesting consideration can be addressed in terms of design point. Due to the good off-design characteristics of the GWA1-18 airfoil, the angle of attack in which the maximum efficiency is reached is almost the same in clean and dirty conditions. For the NACA airfoils, the change in optimal condition is more evident. 


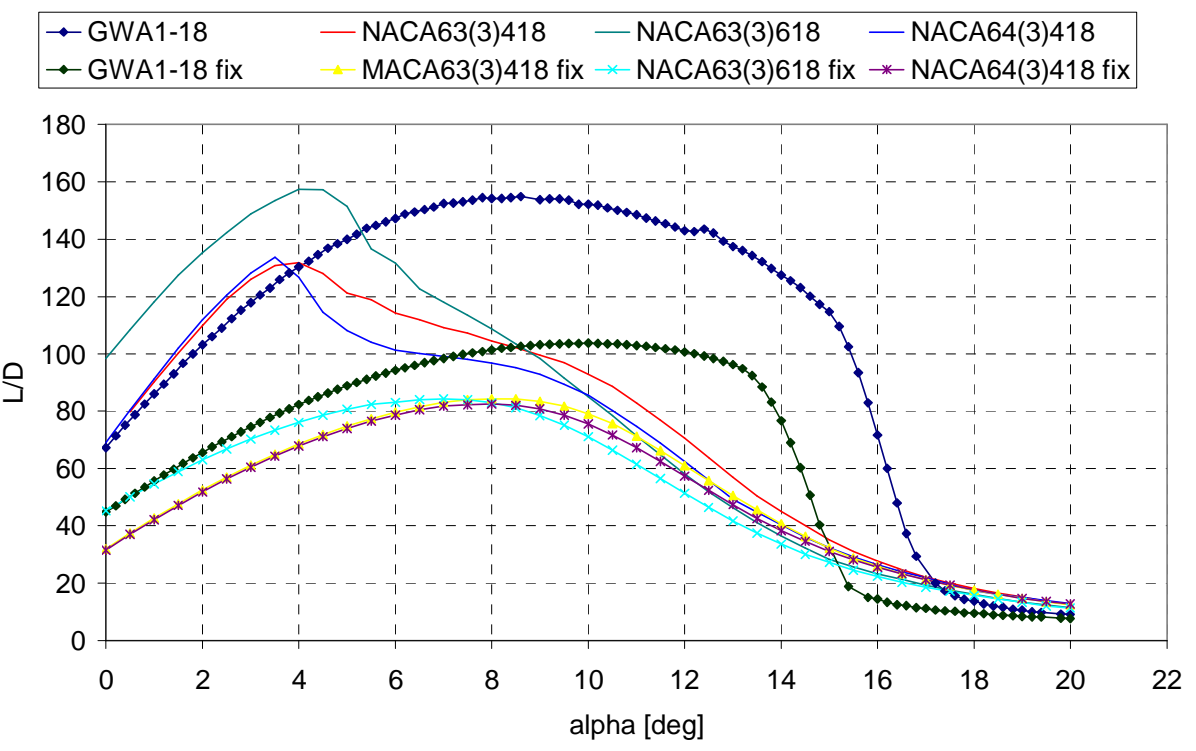

Fig. 13 Lift coefficient curve; comparison between the GWA1-18 and NACA airfoils. Re=6 million, RFOIL predictions. Effect of imposed transition.

2. Effects of Reynolds number and Mach number

The effect related with the Reynolds number has been analyzed. The characteristics of the lift curve and the efficiency curve do not change sensibly; the characteristics at stall and the shape of the efficiency curve are just scaled because of the Reynolds number.

During the design process, the flow is assumed to be incompressible; however, for real Mega-Watt class wind turbines, the velocity at the tip of the blade can reach $90-100 \mathrm{~m} / \mathrm{s}$, that means a Mach number equal to $0.25-0.3$. In Fig. 14 and Fig. 15, the effects due to the Reynods and Mach numbers are shown. According to the RFOIL predictions, the main effects due to the compressibility are an increment in drag at high angles of attack and a shift of the lift curve, but the characteristics of the GWA1-18 airfoil in terms of stall and efficiency characteristics are still good. 


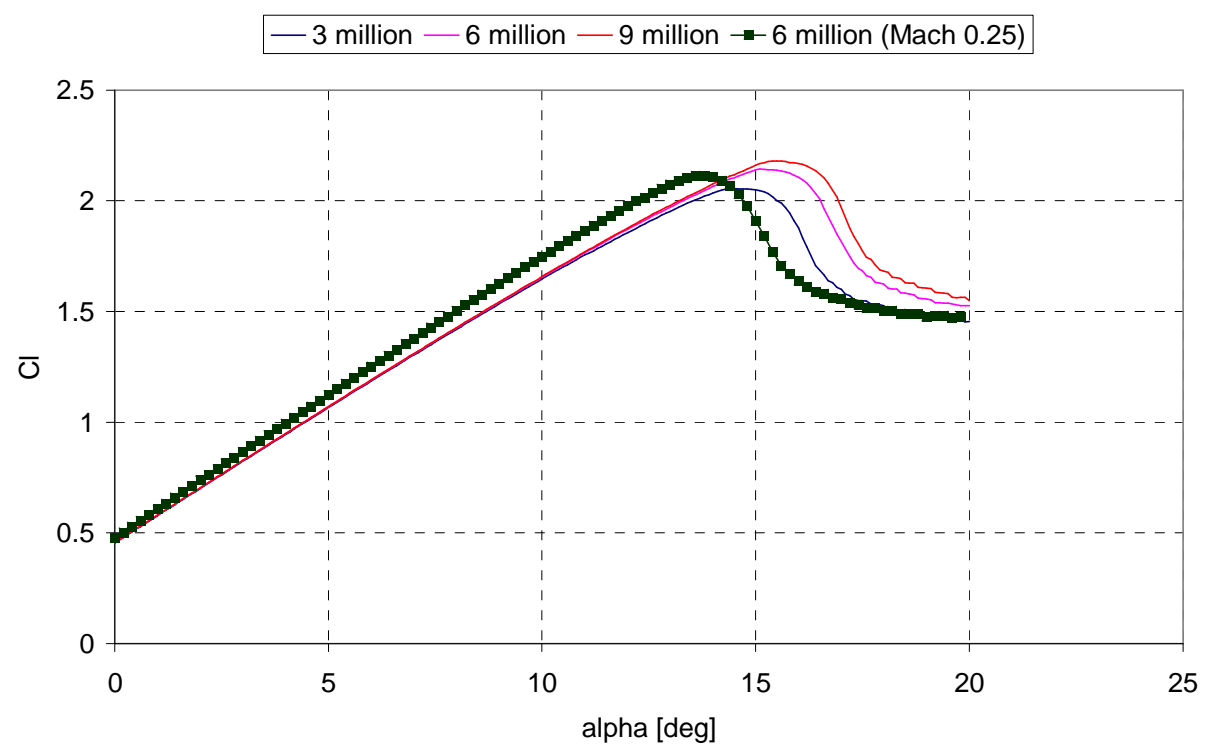

Fig. 14 Lift coefficient curve for the GWA1-18 airfoil; Reynolds number and Mach number effect, RFOIL calculations, free transition.

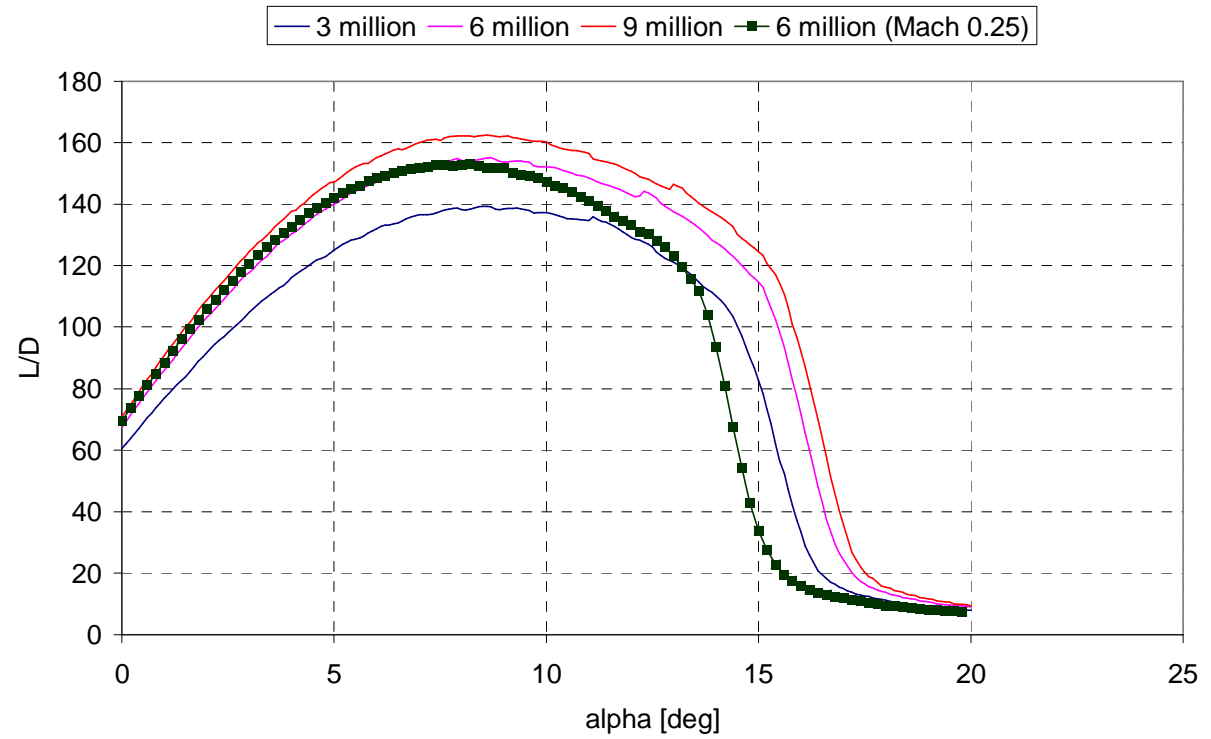

Fig. 15 Efficiency curve for the GWA1-18 airfoil; Reynolds number and Mach number effect, RFOIL calculations, free transition.

\section{Conclusions}

A new airfoil for wind turbines was designed. According to the RFOIL predictions, the results are promising when compared with commonly used NACA airfoils. A very good value for the efficiency was achieved with separation limited only in the stall zone. The high value for the $C_{l}$ can be valuable to reduce chord and thus loads 
and weight to the tip of the blade. Due to the relatively large leading edge radius, the performances in off-design and rough conditions are also good. Also the stall, even if not long as for the NACA airfoils, is quite smooth if considered the high lift character of the GWA1-18 airfoil.

Despite these good results, wind tunnel tests are recommended to validate predictions. Especially for the stall behaviour, the numerical predictions, and consequently the MDO process used in this work, need to be verified. In absence of experimental data, the stall characteristics have been compared with the above mentioned work from Gault; according to these data, the stall for the GWA1-18 airfoil is expected to be due to trailing edge separation.

\section{Acknowledgments}

The author would like to thank Dr. H. Snel for the precious help and suggestions during this work.

\section{References}

[1]. Tangler, J.L., Somers, D.M., "NREL Airfoil Families for HAWT’s”. Proc. WINDPOWER'95, Washington D.C., 1995; pp. $117-123$

[2]. Björk, A., "Coordinates and Calculations for the FFA-W1-xxx, FFA-W2-xxx and FFA-W3-.xxx Series of Airfoils for Horizontal Axis Wind Turbines”. FFA TN 1990-15, Stockholm, Sweden 1990.

[3]. Timmer, W.,A., van Rooij, R.P.J.O.M., "Summary of the Delft University Wind Turbine Dedicated Airfoils". AIAA-20030352.

[4]. Fuglsang, P., Bak, C., "Design and Verification of the new Ris $\emptyset$-A1 Airfoil Family for Wind Turbines”. AIAA-2001-0028.

[5]. Eppler, R., Somers, D.M., “A Computer Program for the Design and Analysis of Low-Speed Airfoils”, NASA-TM-80210, 1980.

[6]. Eppler, R., “Airfoil Design and Data”, Springer Verlag, 1990

[7]. Drela, M., "XFOIL: An Analysis and Design System for Low Reynolds Number Airfoils, Conference on Low Reynolds Number Airfoil Aerodynamics”, University of Notre Dame, June 1989.

[8]. Drela, M., Giles, M.B., "Viscous-Inviscid Analysis of Transonic and Low Reynolds Number Airfoils”, AIAA Journal, Vol. 25, October 1987, pp. 1347-1355.

[9]. Fletcher, R., "Practical Methods of Optimization”, Wiley, 1987.

[10].Pedregal, P., “Introduction to Optimization”, Springer, 2004, ISBN 0-387-40398-1.

[11].Samareh, J., A., "Survey of Shape Parameterization Techniques for High-Fidelity Multidisciplinary Shape Optimization", AIAA Journal, Vol. 39, No. 5, May 2001, pp. 877-884. 
[12].Grasso, F., "Multi-Objective Numerical Optimization Applied to Aircraft Design", Ph.D. Thesis, Dip. Ingegneria Aerospaziale, Università di Napoli Federico II, Napoli, Italy, December 2008.

[13].Schittkowski, K., "NLPQLP: A new Fortran implementation of a sequential quadratic programming algorithm - user's guide, version 1.6”, Report, Department of Mathematics, University of Bayreuth, 2001.

[14].van Rooij, R.P.J.O.M., "Modification of the boundary layer calculation in RFOIL for improved airfoil stall prediction", Report IW-96087R TU-Delft, the Netherlands, September 1996.

[15].Drela, M., "XFOIL 6.94 User Guide”, MIT Aero \& Astro, Dec 2001.

[16].Abbott, I., Von Doenhoff, A., “Theory of Wing Sections”, Dover Publications, Inc., Dover edition, 1958.

[17].ESDU, “The low-speed stalling characteristics of aerodynamically smooth airfoils”, ESDU 66034, October 1966.

[18].Gault, D.E., "A correlation of low-speed airfoil-section stalling characteristics with Reynolds number and airfoil geometry", NACA technical note 3963, Washington, March 1957. 